\section{Orthognathic Surgical Rehabilitation in a Patient with Nemaline Rod Myopathy: A Case Report}

\section{Faisal A Quereshy 1,2, Alyzah U Quereshy², Nick Levintov ${ }^{1,2}$, Manish Valiathan ${ }^{2,3}$, Tarek Elshebiny ${ }^{2,3}$, Humzah A Quereshy ${ }^{4}$ and Dale Baur ${ }^{1,2}$}

1Department of Oral and Maxillofacial Surgery, Case Western Reserve University, Cleveland, USA

${ }^{2}$ Case Western Reserve University School of Dental Medicine, Cleveland, USA

${ }^{3}$ Department of Orthodontics, Case Western Reserve University, Cleveland, USA

${ }^{4}$ Case Western Reserve University School of Medicine, Cleveland, USA

\begin{abstract}
A case report of the 5-year treatment path of a female patient with Nemaline Rod Myopathy treated by the Department of Oral and Maxillofacial Surgery and the Department of Craniofacial Orthodontics at the Case Western Reserve University in Cleveland, Ohio is presented. Myopathic patients present with disease-specific facies that requires extensive surgical intervention. Additionally, these patients are medically complex, requiring extensive pre and post-surgical planning to avoid adverse events. Our multi-disciplinary and multi-staged treatment plan required no extended post-surgical hospital stays or emergent interventions and she was to reach her stated goal of closing her lips and speaking.
\end{abstract}

Keywords: Craniofacial; Lefort; Maxillomandibular fixation; Nemaline rod myopathy; Orthodontics; Orthognathic surgery

\section{Introduction}

Nemaline Myopathy (NM) is a non-progressive disorder that *Corresponding author: Faisal A Quereshy, Department of Oral and Maxillofacial Surgery, Case Western Reserve University, Cleveland, USA, Tel: +1 2163752887; E-mail: faq@case.edu

Citation: Quereshy FA, Quereshy AU, Levintov N, Valiathan M, Elshebiny T, et al. (2020) Orthognathic Surgical Rehabilitation in a Patient with Nemaline Rod Myopathy: A Case Report. J Surg Curr Trend Innov S2: 003.

Received: June 27, 2020; Accepted: July 06, 2020; Published: July 13, 2020

Copyright: ( 2020 Quereshy FA, et al. This is an open-access article distributed under the terms of the Creative Commons Attribution License, which permits unrestricted use, distribution, and reproduction in any medium, provided the original author and source are credited. results in muscle weakness, potentially effecting the whole body [1]. The name arises from the thread or rod-like structures (nemaline bodies) that are seen on muscle biopsy when stained with Gomori Trichrome. Typically an autosomal dominant disorder, NM can either present at birth or rarely acquired as an adult [2].

While the genetic foundation of NM is still under investigation, $\mathrm{NM}$ is thought to be most commonly caused by a mutation in the $\alpha$-actin 1 gene (ACTA1) [2]. Mutations in this specific gene can cause an array of myopathies, all resulting in motor and muscle-relating impairments [2]. Variants in the $\alpha$-actin 1 gene account for about $23 \%$ of nemaline myopathy diagnoses [2]. For example, a missense variant (p.Glu85Lys) in ACTA1, or a mutation at the codon p.Gly253Asp, has the ability to cause nemaline myopathy, resulting in symptoms such as respiratory difficulty and hypotonia [2,3]. Mutations of ACTA1 are typically described as resulting in "dominant distal myopathy with nemaline rods," affecting muscles of the lower arms and legs as well as the hands and feet. Most presentations of NM are autosomal dominant, with very rare presentations of autosomal recessive NM [3].

The clinical presentation of NM varies widely between patients and ranges from muscle weakness to respiratory failure. NM patients are typically classified by six subtypes based upon age of onset and severity of motor and respiratory involvement [4]. In order of decreasing severity, the first classification is described as severe congenital, followed by Amish NM, intermediate congenital, typical congenital, childhood-onset, and adult-onset (late onset). The severe congenital, intermediate congenital, and typical congenital subtypes are noted to have overlap in terms of clinical presentation. The most common subtype is the typical congenital classification and generally preserves a patient's ability to walk [2].

While these classifications help categorize NM patients, individual variation makes it important to highlight the variety of physical symptoms that different patients may show. For example, some patients are hypotonic while others or not, and yet others require tracheostomies and feeding tubes [5].

Congenital nemaline myopathy patients tend to have weakest muscles in the face, dorsiflexors of the feet, flexors of the neck and trunk, and extensors in the toes [6]. Additionally, distal muscles and limb girdle muscles (i.e., muscles away from the torso, limbs, shoulders, thighs, pelvic muscles) are weaker than proximal limb muscles [5]. For those patients that experience pelvic weakness but can walk, a characteristic myopathic gait is commonly seen [6]. These examples of muscle weakness can be attributed to significant atrophy [7].

Oral and pharyngeal muscles are often compromised in NM patients, resulting in compromised speech and swallowing. Symptoms that arise from this weakness include feeding problems at infancy, hyper-nasal speech, dysarthria, high-arch palate, missing palatal reflex, furrowed tongue, and jaw contractures [5]. In addition to the high-arched palate, other skeletal deformities include kyphosis, scoliosis, pes cavus, and pigeon chest [6]. For NM patients with respiratory muscle weakness and restricted respiratory pathways, respiratory 
tract infections can occur frequently and can cause death, especially in pediatric cases. Patients will also experience mild facial muscle weakness and hypomimia (reduced facial expression) [6,7].

While there are not many publications describing orthognathic surgery specifically on nemaline myopathy cases, there is published literature for similar cases. Orthognathic surgery for patients with neuromuscular disorders is meant to provide improvement in "oral function, facial esthetics, social acceptance, and general quality of life" [8]. In 2008, a case report by Kriwalsky, et al. discussed an orthognathic surgery performed on a 20 -year-old female patient with infantile Facioscapulohumeral Muscular Dystrophy (FSHD). Based upon the report, the characteristics of FSHD, also an autosomal dominant disorder, are very similar to the NM manifestations (i.e., myopathy involving facial muscles, shoulders and upper arm muscles, pelvic muscles, as well as scoliosis).

\section{Case Report}

A female, 14 years and 8 months of age, with nemaline rod myopathy was referred to the Department of Oral \& Maxillofacial Surgery by the Craniofacial Orthodontics Department at Case Western Reserve University (CWRU) for reconstructive jaw surgery consultation (Figure 1). Her chief complaint, according to her mother, was that she was unable "to close her mouth and talk."

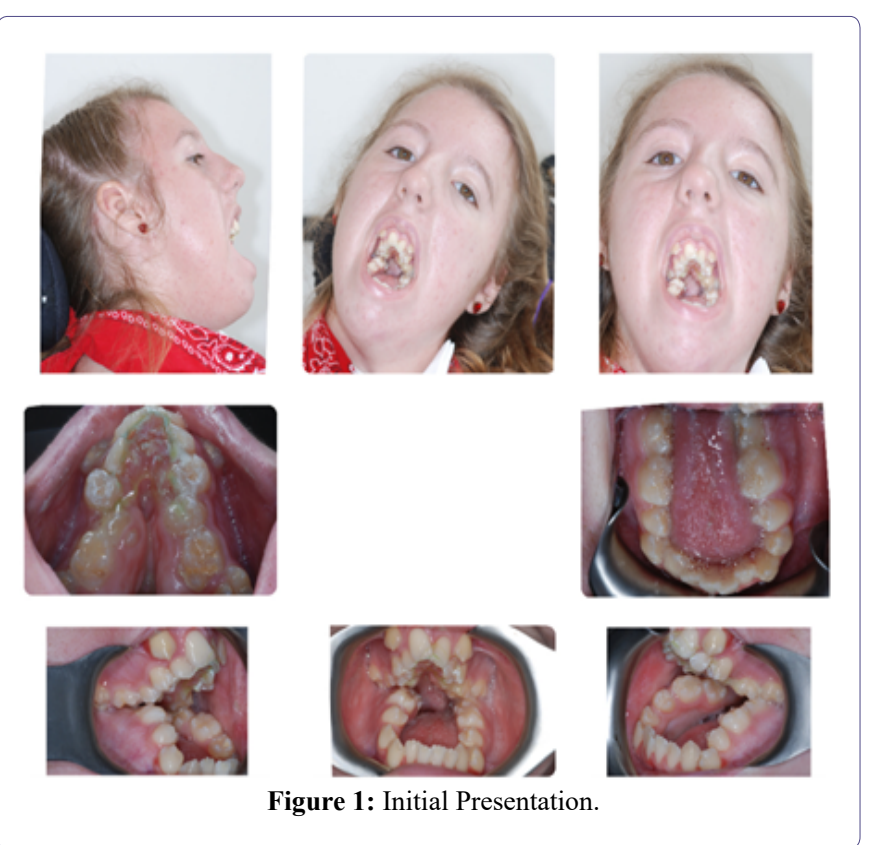

The patient had an extensive past surgical history beginning at 2 months of age with undergoing gastric tube placement. By 1 year of age, the patient had a tracheostomy and became ventilator dependent. Also, by 1 year of age, she had a nissen fundoplication. The patient had several orthopedic procedures, as well, with the earliest being at 4 years of age, at which point she received orthopedic rods for treatment of scoliosis. At 8 years of age, the patient underwent bilateral submandibular gland excision, bilateral submandibular ganglion electrocauterization, and left stenson's duct ligation.

Surgical workup involved obtaining standard facial and intra-oral photographs, impressions for models, facebow transfer, and occlusion as per the patient's most appropriate centric relation position. CT of facial bones and intra-oral scan (iTero Element ${ }^{\circledR}$ ) were also completed.

Her facial soft tissue diagnosis consisted of a dolichofacial pattern with a convex profile. Her facial asymmetry was observed with the nose deviated to the right, and the upper dental midline to the left and the mandible to the left, when compared to the facial midline. An increased lower facial height was also observed, with incompetent lips due to the skeletal open bite and a short upper lip. The nasolabial angle was obtuse, and the chin was weak.

Three skeletal diagnoses were given: maxillary and mandibular retrognathia, a hyperdivergent vertical relationship, and a very narrow and high-arched palate in transverse dimension. The list of dental problems included an angle class III molar relationship, a negative overjet with retroclined upper and lower incisors, a severe open bite, a reverse curve of spee in the lower arch, a deep curve of Wilson, and a severe arch length discrepancy between the maxilla and mandible.

The treatment objectives were to restore maxillomandibular harmony with facial esthetics. Addressing the significant lip incompetence and the almost straight gonial angle were among the main objectives. All three planes of skeletal dimension were addressed to correct retrognathia, hyperdivergent pattern, and severe maxillary transverse discrepancy. Dental goals involved normalizing position and inclination of incisors, obtaining normal overjet and overbite, alleviating crowding, and flattening the curve of Spee and Wilson.

To address the patient's chief complaint, a combined orthodontic and orthognathic approach was proposed to the family. Given the complexity and severity of the case, a three-phase plan was presented.

\section{Stages of Surgery}

\section{Surgery 1}

Initially, the fourteen-year old patient underwent surgically assisted rapid palatal expansion, extraction of extruded lower first permanent molars \#19 and 30, and fixation of bilateral orthopedic anchorage devices to the posterior mandibular alveolus. The goal of surgically assisted rapid palatal expansion was to widen the severely constricted maxillary arch and reduce crowding. The goal of extracting teeth \#19 and 30 was to alleviate the crowding of the lower dentition. Bilateral orthopedic anchoring devices were placed to intrude the lower molars and decrease the open bite by allowing for autorotation of the mandible. EBL was $350 \mathrm{cc}$. She was admitted to the Pediatric Intensive Care Unit (PICU) (Figure 2).

\section{Surgery 2}

When the patient was 16 years of age, the second stage surgery was completed, including a complete, segmental, 3-piece Le Fort I osteotomy with the extraction of upper first premolars \#5 and 12. This surgery aimed to impact and widen the maxilla. The extraction of the upper teeth was carried out to alleviate the remaining arch length deficiency. Post-surgical orthodontics focused on the leveling, alignment, and coordination of the dental arches prior to the last phase.

\section{Surgery 3}

The final reconstructive surgery was completed when the patient was 20 years of age. At this point, the maxillary and mandibular 
arches were aligned and the patient presented for a surgical work up (Figure 3).
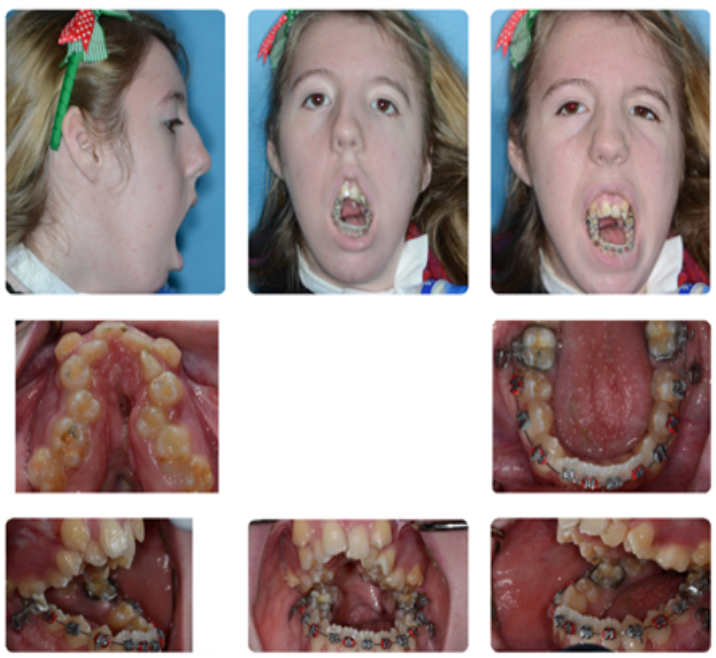

Figure 2: Post-SARPE and Orthodontic Expansion.
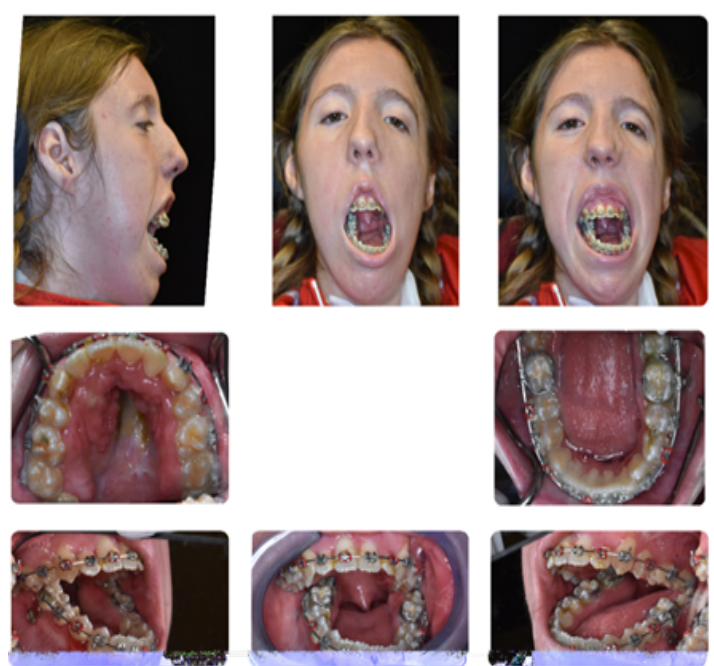

Figure 3: Final Surgical Work Up.

Presurgical dentofacial findings included a dolichocephalic facial pattern; apertognathia with a $20.5 \mathrm{~mm}$ open bite; maxillary retrognathia; vertical maxillary excess of $100 \%$ tooth show with $2 \mathrm{~mm}$ of gingival show at rest; and an almost-straight mandibular gonial angle of 164 degrees. Excessive lower anterior facial height was evident due to the straight mandibular angle and the patient's inability to close her mouth. Her inability to close was due to a combination of mechanical and skeletal interferences with decompensated muscle weakness.

The final dento-skeletal positions were planned using medical modelling and virtual surgical planning. The occlusion was determined and approved by the craniofacial orthodontic and maxillofacial surgical teams. It was set with virtual surgical planning and confirmed during the planning session with study models.
The first portion of the surgery consisted of vertical correction with a $10 \mathrm{~mm}$ impaction, antero-posterior correction with a $5 \mathrm{~mm}$ advancement, and a yaw correction with a $0.9 \mathrm{~mm}$ movement to the right. Previous maxillary hardware was removed prior to the completion of osteotomies. The right and left maxillary sinuses were composed of pneumatized trabecular air cells. The impaction was completed with the aid of custom printed bone reduction guides. The anterior nasal spine was augmented and surgically sculpted after impaction and prior to internal fixation. An intermediate splint was used to place the patient into Maxillomandibular Fixation (MMF) prior to internal fixation. The internal fixation was completed with bilateral nasomaxillary buttress plates and bilateral zygomaticomaxillary buttress plates.

The second portion focused on the mandible. Access to the mandibular rami and angle were achieved via bilateral risdon incisions. Right and left extraoral inverted L osteotomies were completed using custom cutting guides. Precise osteotomies were completed using a reciprocating saw for the vertical osteotomy and right-angle oscillating saw for the horizontal osteotomy. In addition, the fixation holes for the cutting guides lined up with the fixation holes of the final custom reconstruction plate. The patient was placed into wire maxillomandibular fixation using the final splint. A $2.8 \mathrm{~mm}$ reconstruction plate was used for rigid internal fixation. Counterclockwise rotation of the mandible was achieved. Due to chronic shortening of the supra-hyoid musculature, a suprahyoid myotomy of the anterior belly of the digastric muscle was completed by releasing it from the symphysis. This decreased the tension and shortened muscle retraction forces.

Prior to transfer to the surgical intensive care unit, the patient was taken off all general anesthetics. Her endotracheal tube was exchanged for her custom tracheostomy tube. The patient was placed back on ventilator support as baseline requirements and stayed in the ICU for 1.5 days. The patient was then transferred to the Rainbow Babies Children's Hospital- University Hospitals, to the pediatric pulmonology floor, and co-managed with the service that took care of her during previous admissions. She stayed on the pediatric pulmonology floor for 1.5 days and was discharged home on Post-operative day \#3.

At the two-week post-op orthodontic visit, the wire MMF was removed and replaced with guiding elastics. Routine post-orthognathic healing was noted at this appointment (Figures 4 and 5). Two months following surgery, the upper and lower orthodontic wires were changed to aid in coordination of the arches. Once stable Class 1 occlusion with satisfactory overjet and overbite was achieved, the braces were removed. Elastics were placed on MMF screws that were placed during the third surgery in an attempt to aid in maintaining comfortable closure of the mouth; however, the patient requested MMF screws be removed due to discomfort. A chin cup was then created to assist in passive closure and fixed upper and lower retainers placed with additional removable palate stabilizing devices.

\section{Discussion}

Nemaline Myopathy is a congenital hereditary neuromuscular disorder that causes muscle weakness. The prevalence is approximately $1: 22,480$ [9]. First defined in 1963, it is a disease of voluntary muscle. Patients exhibit myopathy throughout the body, but it is typically most severe in the muscles of the face, neck, and limbs. This case report discusses a combined orthodontic and orthognathic treatment of a female patient with nemaline rod myopathy over a course of 
Citation: Quereshy FA, Quereshy AU, Levintov N, Valiathan M, Elshebiny T, et al. (2020) Orthognathic Surgical Rehabilitation in a Patient with Nemaline Rod Myopathy: A Case Report. J Surg Curr Trend Innov S2: 003.

six years at Case Western Reserve University Department of Orthodontics and Oral \& Maxillofacial Surgery.
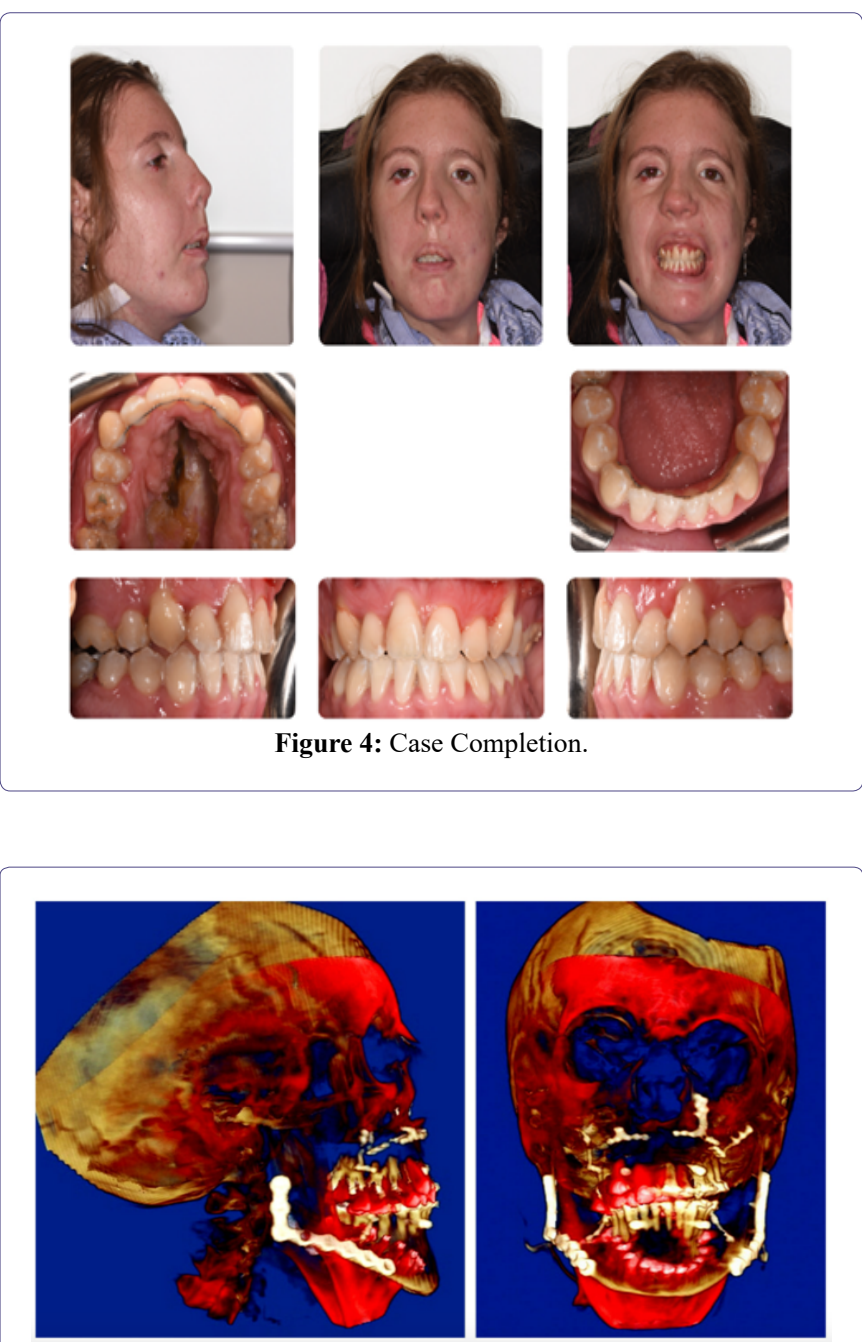

Figure 5: Superimposition: Red is Initial Bony Positions and Brown is Final Bony Positions.

This is the first reported case detailing an extensive orthodontic and surgical history of a patient with nemaline rod myopathy from a late-mixed dentition stage to corrective jaw surgery. Although our patient's available medical records do not identify her NM subtype, analysis of her neonatal history and disease progression is most consistent with the severe congenital subtype.

Current literature on the management of facial, skeletal, and dental discrepancies in NM patients is limited and contradictory. In the "Consensus Statement on Standard of Care for Congenital Myopathies," published in 2012, Wang et al. does not recommend surgical treatment of severe malocclusion due to high risk of serious complications from intubation and anesthesia. According to Wang et al., "Malignant hyperthermia is always a concern in myopathic patients undergoing general anesthesia." Additionally, Wang et al suggests succinylcholine and inhalational agents should be avoided, and safe intravenous agents should be used instead [10]. Oliveira, et al. published a case report using sevoflurane in a pediatric patient with nemaline rod myopathy. He explains an association between nemaline rod myopathy and malignant hyperthermia has never been established [11]. Additionally, NM has never been associated with a known malignant hyperthermia-associated RyR1 mutation [12].

Ryan, et al. reported 130 NM patients who underwent 1 or more surgical procedures [13]. No malignant hyperthermia was reported, but five patients did develop unexpected postoperative respiratory failure. The patient from our case study underwent multiple surgeries without such complications. Also, her family history shows no significant susceptibility for malignant hyperthermia. The surgical team still treated this risk carefully and the anesthesiology team used only Total Intravenous Anesthesia (TIVA). Cardiopulmonary monitoring was maintained during and after the procedure and dantrolene was made available.

Bezak, et al. presented a case series of 6 patients with congenital myopathy and congenital dystrophy who underwent orthognathic surgery: 5 female and 1 male with an average age of 19.5 years. Three of the patients had congenital myopathy with one detailed as having NM. The patients with congenital myopathy had similar dentofacial findings and underwent similar corrective jaw surgery, all receiving Le Fort I osteotomy and either Bilateral Sagittal Split Osteotomy (BSSO) or Extraoral Vertical Ramus Osteotomy (EVRO) [14].

The magnitude of skeletal discrepancies in our patient were extraordinary and required relatively unprecedented bony movements. For example, the presurgical records included an open bite of 20.5 $\mathrm{mm}$ and a mandibular gonial angle of 164 degrees. As a result, we cannot use studies conducted on average surgical open bite corrections to predict stability in this patient [15]. While superior maxillary repositioning is considered the most stable orthognathic movement, the stability of an upper jaw impaction of $10 \mathrm{~mm}$ is not equally predictable [16]. Additionally, muscular weakness poses another challenge to maintain a positive incisor overlap. During the mandibular surgery, a suprahyoid myotomy of the anterior belly of the digastric muscle was done to reduce any risk of relapse related to previous shortening of the suprahyoid muscles.

According to Bagnall, et al., facial weakness and malocclusion in NM patients increase the effort required to seal lips and produce bilabial sounds [17]. This facial weakness can progress and lead to anterior open bite which will worsen the lip seal. According Bagnall, there is no current specific intervention to overcome this structural facial progression.

In this report, our patient's myopathic facies was grossly evident and corrected by staged surgical means. Her condition precluded improvement or opportunity to speak full sentences. The patient is tracheostomy and ventilator dependent. Her ability to produce sounds is physiologically limited by her restrictive lung disease, minimal tidal volumes, ventilator requirements, and muscle weakness to the extent that it is difficult to produce the strength to sustain a sentence. The patient communicated well through writing and sign language throughout the course of treatment. Even though the patient is not intellectually disabled and graduated high school in a timely manner, the psychosocial effects of her condition encourage intervention. After recovery, she started to produce some oro-nasal sounds in response to polar questions. Post-operatively, she was referred to her speech therapist for more evaluation. 


\section{Conclusion}

We present a case report of a 20 -year-old female with nemaline rod myopathy treated with orthognathic surgery to correct her maxillomandibular myopathic facies. A thorough history of combined orthodontic and surgical therapy from the age of 14 to the age of 20 is detailed. Stage 3 definitive surgery involved maxillary Le Fort I impaction of $10 \mathrm{~mm}$ with $5 \mathrm{~mm}$ advancement, anterior correction $5 \mathrm{~mm}$ to right and posterior yaw correction, and cant correction. Mandibular surgery involved bilateral extraoral inverted L osteotomy with the counterclockwise rotation of the mandible to the final maxillary position, and suprahyoid myotomy. Net change in chin point was $4 \mathrm{~cm}$ due to the magnitude of counterclockwise mandibular rotation. Hospital stay was short, considering the patient's medical comorbidities. The patient's quality of life significantly improved. With a new, improved tongue-palate relationship and the correction of her severe lower lip incompetence, the patient was able to produce some words.

In conclusion, early medical intervention for patients with a severe subtype of congenital nemaline myopathy can lead to a fulfilling life for these patients. Intellect is not affected and these patients can interact with others as long as they can adapt their communication methods. Although NM is a nonprogressive disease, in a muscular sense, and although patients live with the condition depending on their subtype, myopathic facies is a progressive manifestation of the disease. More research is needed to identify the true risks of intervention and to develop protocols to address the typical dentofacial abnormalities common to this disease.

\section{Competing Interests}

None.

\section{Funding}

None.

\section{References}

1. Xue Y, Magoulas PL, Wirthlin JO, Buchanan EP (2017) Craniofacial Manifestations in Severe Nemaline Myopathy. J Craniofac Surg 28: 258-260.

2. Lehtokari VL, Gardberg M, Pelin K, Wallgren-Pettersson C (2018) Clinically variable nemaline myopathy in a three-generation family caused by mutation of the skeletal muscle alpha-actin gene. Neuromuscul Disord 28: 323-326.

3. Liewluck T, Sorenson EJ, Walkiewicz MA, Rumilla KM, Milone M (2017) Autosomal dominant distal myopathy due to a novel ACTA1 mutation. Neuromuscul Disord 27: 742-746.
4. Maggi L, Scoto M, Cirak S, Robb SA, Klein A, et al. (2013) Congenital myopathies--clinical features and frequency of individual subtypes diagnosed over a 5-year period in the United Kingdom. Neuromuscul Disord 23: $195-205$.

5. Martinez BA, Lake BD (1987) Childhood nemaline myopathy: a review of clinical presentation in relation to prognosis. Dev Med Child Neurol 29: $815-820$

6. Wallgren-Pettersson C (1989) Congenital nemaline myopathy: A clinical follow-up of twelve patients. J Neurol Sci 89: 1-14.

7. Hopkins IJ, Lindsey JR, Ford FR (1966) Nemaline myopathy. A long-term clinicopathologic study of affected mother and daughter. Brain J Neurol 89: $299-310$.

8. Kriwalsky MS, Deschauer M, Eckert AW, Schubert J, Zierz S (2008) Orthognathic surgery in a case of infantile facioscapulohumeral muscular dystrophy with macroglossia. Oral Maxillofac Surg 12: 195-198.

9. Amburgey K, McNamara N, Bennett LR, McCormick ME, Acsadi G, et al. (2011) Prevalence of congenital myopathies in a representative pediatric united states population. Ann Neurol 70: 662-665.

10. Wang CH, Dowling JJ, North K, Schroth MK, Sejersen T, et al. (2012) Consensus statement on standard of care for congenital myopathies. J Child Neurol 27: 363-382.

11. Oliveira M, Fernandes AL, Vargas S (2018) Using sevoflurane in a pediatric patient with nemaline rod myopathy. Paediatr Anaesth 28: 749-750.

12. Brislin RP, Theroux MC (2013) Core myopathies and malignant hyperthermia susceptibility: A review. Paediatr Anaesth 23: 834-841.

13. Ryan MM, Schnell C, Strickland CD, Shield LK, Morgan G, et al. (2001) Nemaline myopathy: a clinical study of 143 cases. Ann Neurol 50: 312 320 .

14. Bezak BJ, Arce KA, Jacob A, Van Ess J (2016) Orthognathic Surgery in Patients With Congenital Myopathies and Congenital Muscular Dystrophies: Case Series and Review of the Literature. J Oral Maxillofac Surg 74: 601-609.

15. Proffit WR, Bailey LJ, Phillips C, Turvey TA (2000) Long-term stability of surgical open-bite correction by Le Fort I osteotomy. Angle Orthod 70: 112-117.

16. Proffit WR, Turvey TA, Phillips C (1996) Orthognathic surgery: a hierarchy of stability. Int J Adult Orthodon Orthognath Surg 11: 191-204.

17. Bagnall AK, Al-Muhaizea MA, Manzur AY (2006) Feeding and speech difficulties in typical congenital Nemaline Myopathy. Adv Speech Lang Pathol 8: 7-16 


\section{di \\ нетан}

Advances In Industrial Biotechnology | ISSN: 2639-5665

Advances In Microbiology Research | ISSN: 2689-694X

Archives Of Surgery And Surgical Education | ISSN: 2689-3126

Archives Of Urology

Archives Of Zoological Studies | ISSN: 2640-7779

Current Trends Medical And Biological Engineering

International Journal Of Case Reports And Therapeutic Studies | ISSN: 2689-310X

Journal Of Addiction \& Addictive Disorders | ISSN: 2578-7276

Journal Of Agronomy \& Agricultural Science | ISSN: 2689-8292

Journal Of AIDS Clinical Research \& STDs | ISSN: 2572-7370

Journal Of Alcoholism Drug Abuse \& Substance Dependence | ISSN: 2572-9594

Journal Of Allergy Disorders \& Therapy | ISSN: 2470-749X

Journal Of Alternative Complementary \& Integrative Medicine | ISSN: 2470-7562

Journal Of Alzheimers \& Neurodegenerative Diseases | ISSN: 2572-9608

Journal Of Anesthesia \& Clinical Care | ISSN: 2378-8879

Journal Of Angiology \& Vascular Surgery | ISSN: 2572-7397

Journal Of Animal Research \& Veterinary Science | ISSN: 2639-3751

Journal Of Aquaculture \& Fisheries | ISSN: 2576-5523

Journal Of Atmospheric \& Earth Sciences | ISSN: 2689-8780

Journal Of Biotech Research \& Biochemistry

Journal Of Brain \& Neuroscience Research

Journal Of Cancer Biology \& Treatment | ISSN: 2470-7546

Journal Of Cardiology Study \& Research | ISSN: 2640-768X

Journal Of Cell Biology \& Cell Metabolism | ISSN: 2381-1943

Journal Of Clinical Dermatology \& Therapy | ISSN: 2378-8771

Journal Of Clinical Immunology \& Immunotherapy | ISSN: 2378-8844

Journal Of Clinical Studies \& Medical Case Reports | ISSN: 2378-8801

Journal Of Community Medicine \& Public Health Care | ISSN: 2381-1978

Journal Of Cytology \& Tissue Biology | ISSN: 2378-9107

Journal Of Dairy Research \& Technology | ISSN: 2688-9315

Journal Of Dentistry Oral Health \& Cosmesis | ISSN: 2473-6783

Journal Of Diabetes \& Metabolic Disorders | ISSN: 2381-201X

Journal Of Emergency Medicine Trauma \& Surgical Care | ISSN: 2378-8798

Journal Of Environmental Science Current Research | ISSN: 2643-5020

Journal Of Food Science \& Nutrition | ISSN: 2470-1076

Journal Of Forensic Legal \& Investigative Sciences | ISSN: 2473-733X

Journal Of Gastroenterology \& Hepatology Research | ISSN: 2574-2566
Journal Of Genetics \& Genomic Sciences | ISSN: 2574-2485

Journal Of Gerontology \& Geriatric Medicine | ISSN: 2381-8662

Journal Of Hematology Blood Transfusion \& Disorders | ISSN: 2572-2999

Journal Of Hospice \& Palliative Medical Care

Journal Of Human Endocrinology | ISSN: 2572-9640

Journal Of Infectious \& Non Infectious Diseases | ISSN: 2381-8654

Journal Of Internal Medicine \& Primary Healthcare | ISSN: 2574-2493

Journal Of Light \& Laser Current Trends

Journal Of Medicine Study \& Research | ISSN: 2639-5657

Journal Of Modern Chemical Sciences

Journal Of Nanotechnology Nanomedicine \& Nanobiotechnology | ISSN: 2381-2044

Journal Of Neonatology \& Clinical Pediatrics | ISSN: 2378-878X

Journal Of Nephrology \& Renal Therapy | ISSN: 2473-7313

Journal Of Non Invasive Vascular Investigation | ISSN: 2572-7400

Journal Of Nuclear Medicine Radiology \& Radiation Therapy | ISSN: 2572-7419

Journal Of Obesity \& Weight Loss | ISSN: 2473-7372

Journal Of Ophthalmology \& Clinical Research | ISSN: 2378-8887

Journal Of Orthopedic Research \& Physiotherapy | ISSN: 2381-2052

Journal Of Otolaryngology Head \& Neck Surgery | ISSN: 2573-010X

Journal Of Pathology Clinical \& Medical Research

Journal Of Pharmacology Pharmaceutics \& Pharmacovigilance | ISSN: 2639-5649

Journal Of Physical Medicine Rehabilitation \& Disabilities | ISSN: 2381-8670

Journal Of Plant Science Current Research | ISSN: 2639-3743

Journal Of Practical \& Professional Nursing | ISSN: 2639-5681

Journal Of Protein Research \& Bioinformatics

Journal Of Psychiatry Depression \& Anxiety | ISSN: 2573-0150

Journal Of Pulmonary Medicine \& Respiratory Research | ISSN: 2573-0177

Journal Of Reproductive Medicine Gynaecology \& Obstetrics | ISSN: 2574-2574

Journal Of Stem Cells Research Development \& Therapy | ISSN: 2381-2060

Journal Of Surgery Current Trends \& Innovations | ISSN: 2578-7284

Journal Of Toxicology Current Research | ISSN: 2639-3735

Journal Of Translational Science And Research

Journal Of Vaccines Research \& Vaccination | ISSN: 2573-0193

Journal Of Virology \& Antivirals

Sports Medicine And Injury Care Journal | ISSN: 2689-8829

Trends In Anatomy \& Physiology | ISSN: 2640-7752

Submit Your Manuscript: https://www.heraldopenaccess.us/submit-manuscript 